\title{
Experimental and Numerical Investigation of Nanofluid Usage in A Plate Heat Exchanger for Performance Improvement
}

\author{
Adnan Sözen, Ataollah Khanları and Erdem Çiftçi*
}

Gazi University Energy Systems Engineering Department, Ankara, Turkey

\begin{abstract}
Plate heat exchangers, a compact-type heat exchanger, are commonly used heat transfer devices because of their superior characteristics. Their thermal performances are strongly dependent to working fluid circulating inside the system. The influences of nanofluid utilization as the working fluid in a plate heat exchanger was experimentally and numerically analysed in this study. In order to show off the improvement rate in heat transfer, the experiments were performed by using deionized water and TiO2-deionized water nanofluid. The nanofluid was prepared at the rate of $1.5 \%$ as weighted. A surface-active agent, Triton X-100, was also doped into the mixture at the rate of $0.2 \%$ of a final concentration to prevent the sedimentation and flocculation of the nanoparticles inside the solution. The experiments were performed in different temperatures as $40^{\circ} \mathrm{C}, 45^{\circ} \mathrm{C}, 50^{\circ} \mathrm{C}$ and varying cold fluid mass flow rates as $3,4,5,6$ and 7 lpm. In addition, using the experimental data, a numerical simulation was realized by ANSYS Fluent software. The both results indicate that heat transfer rate in plate heat exchanger can be improved using nanofluid as the working fluid in place of deionized water. The maximum improvement rate in heat transfer was obtained as $11 \%$ in experimental study. It is also seen that experimental and numerical results are in good agreement.
\end{abstract}

C2019. CBIORE-IJRED. All rights reserved

Keywords: Plate heat exchanger, Nanofluid, Heat transfer enhancement, Performance, Numerical analysis.

Article History: Received May 18 th 2018; Received in revised form October 17th 2018; Accepted January $8^{\text {th }}$ 2019; Available online How to Cite This Article: Sözen, A., Khanlari, A., and Çiftçi, E. (2019) Experimental and Numerical Investigation of Nanofluid Usage in a Plate Heat Exchanger for Performance Improvement. Int. Journal of Renewable Energy Development, 8(1), 27-32. https://doi.org/10.14710/ijred.8.1.27-32

\section{Introduction}

Energy efficiency has become the most popular subject in recent years, especially in heat transfer applications. It is an incontrovertible fact that heat exchangers are widely used heat transfer equipment in industry. They have plenty of different types according to the usage area of them. Plate heat exchangers, a compact-type heat exchanger, are commonly used heat transfer devices in combi boilers due to their superior characteristics. They operate at temperatures under $250^{\circ} \mathrm{C}$ and pressures below 40 bar. Thermal performance of plate heat exchangers is affected by plate geometry, plate number, plate thickness and chevron angle. The effects of geometrical parameters of plate heat exchanger on heat transfer rate and pressure drop have been subjected in many academic studies (Yang et al. 2017). In addition, thermal performance of plate heat exchanger is considerably affected by working fluid. Although there are lots of methods are available in literature to improve the thermal characteristics of plate heat exchangers, the most preferred method is upgrading the thermophysical properties of the working fluid (Behrangzadeh \& Heyhat 2016; Barzegarian et al. 2016; Huang et al. 2016; Sarafraz \& Hormozi 2016; TaghizadehTabari et al. 2016).
To illustrate, Tiwari et al. tested $\mathrm{SiO}_{2} /$ water, $\mathrm{CeO}_{2} /$ water, $\mathrm{TiO}_{2} /$ water and $\mathrm{Al}_{2} \mathrm{O}_{3} /$ water nanofluids in the plate heat exchanger with the aim of determining the best working fluid in terms of thermal performance. They demonstrated that $\mathrm{CeO}_{2} /$ water exhibited better performance than the other ones (Tiwari et al. 2013). Kumar et al. (2016) studied the influence of chevron angle on heat transfer rate by using $\mathrm{ZnO} /$ deionized water. They tested symmetrical $\left(30^{\circ} / 30^{\circ}\right.$ and $\left.60^{\circ} / 60^{\circ}\right)$ and unsymmetrical $\left(30^{\circ} / 60^{\circ}\right)$ chevron angles and indicated that $60^{\circ} / 60^{\circ}$ symmetrical chevron angle gave the better results (Kumar et al. 2016). Kabeel et al. studied $\mathrm{Al}_{2} \mathrm{O}_{3} /$ water nanofluid usage as the working fluid with different particle concentrations in plate heat exchanger. Their experimental results showed that maximum improvement in heat transfer coefficient was achieved as $13 \%$ at $4 \%$ particle concentration (Kabeel et al. 2013). Pandey and Nema (2012) investigated $\mathrm{Al}_{2} \mathrm{O}_{3} /$ water nanofluid with $2 \%, 3 \%$ and $4 \%$ volume concentrations in the plate heat exchanger. They indicated that overall heat transfer coefficient improved between $4.6-10 \%$ by using $\mathrm{Al}_{2} \mathrm{O}_{3} /$ water nanofluid. In another study, Serebryakova et al. (2015) tested a hybrid base fluid (ethylene glycol and water) and alumina nanoparticles at the rate of $1.5 \%$ to constitute a new nanofluid. They investigated the

\footnotetext{
* Corresponding author: erdemciftci@gazi.edu.tr
} 
increment in thermal conductivity of this nanofluid, when it is used as working fluid in heat transfer applications.

Furthermore, some researchers investigated plate heat exchanger characteristics numerically by using CFD approach. Tiwari et al. (2014) simulated heat transfer in a plate heat exchanger assuming $\mathrm{CeO}_{2}$ /water and $\mathrm{Al}_{2} \mathrm{O}_{3} /$ water as homogenous fluids. In addition, they analyzed nanofluids experimentally to verify their numerical model. The obtained results demonstrated that their CFD model could be used to predict thermal behavior of various nanofluids. Han et al. (2014) developed a 3D CFD model to predict thermal characteristics of a plate heat exchanger. They reported that plate type, plate number and fluid flow direction had important effects on heat transfer in a plate heat exchanger. Kan et al. (2012) numerically investigated the effects of plate channel angle and fluid mass flow rate on heat transfer in the plate heat exchanger. The numerically obtained results indicated that plate channels with $30^{\circ}$ angle has better thermal performance than the others.

In this study, nanoparticle-including working fluid, i.e. nanofluid, was utilized as the working fluid in a plate heat exchanger for varying temperature and cold fluid flow rates. The experiments were conducted for both deionized water and $\mathrm{TiO} 2$-deionized water nanofluid. Using the obtained results from the experiments, a numerical study was also performed to visualize the findings. Alterations in heat transfer rate for each working fluid was determined numerically and experimentally.

\section{Materials and Methods}

$\mathrm{TiO}_{2}$ particles were grained to nano scales with average sizes of $46 \mathrm{~nm}$ to prepare a nanofluid. The nanofluid suspension had 1.5\% nanoparticle content as weighted. Nanoparticles were doped into the deionized water. A surfactant material was added into the mixture to prevent not just the flocculation, but also the precipitations of nanoparticles during operation. In addition, surfactants have a role on decreasing surface tension and increasing wetting capability of the solution. The thermophysical properties of prepared nanofluid can be seen in Table 1 .

Table 1

Thermophysical properties of TiO2/deionized water nanofluid

\begin{tabular}{|c|c|c|c|c|c|c|}
\hline \multirow{2}{*}{ Working fluid } & \multicolumn{4}{|c|}{ Viscosity (mPa.s) } & \multirow{2}{*}{$\begin{array}{r}\text { Density } \\
\left(\mathrm{kg} / \mathrm{m}^{3}\right)\end{array}$} & \multirow{2}{*}{$\begin{array}{l}\text { Heat capacity } \\
\text { (kJ/kgK) }\end{array}$} \\
\hline & $20^{\circ} \mathrm{C}$ & $40^{\circ} \mathrm{C}$ & $60^{\circ} \mathrm{C}$ & $80^{\circ} \mathrm{C}$ & & \\
\hline Water & 0.98 & 0.64 & 0.45 & 0.35 & 998 & 4.18 \\
\hline $\mathrm{TiO}_{2} /$ water & 1.01 & 0.92 & 0.67 & 0.54 & 1015 & 4.26 \\
\hline
\end{tabular}

The schematic diagram of the test rig was given in Figure 1. Figure 1 shows the test rig includes a coiled heat exchanger, heater, circulation pump, plate heat exchanger, flow meter and K-type four thermocouples. 16 stainless-steel corrugated plates with the corrugation angle of $60^{\circ}$ form the plate heat exchanger. A general view and geometrical properties of plate heat exchanger used in experiments were illustrated in Figure 2 and Table 2, respectively.

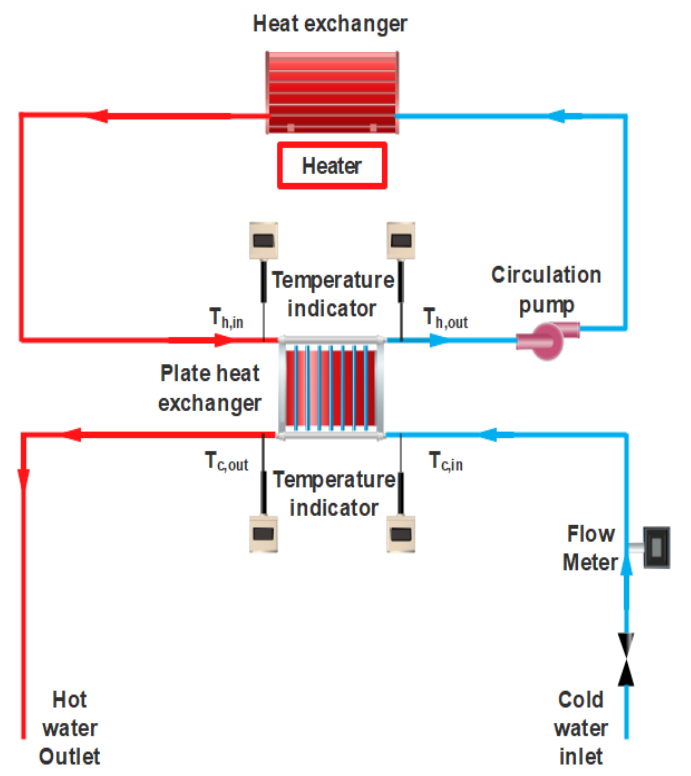

Fig. 1 Schematic diagram of the experimental set up

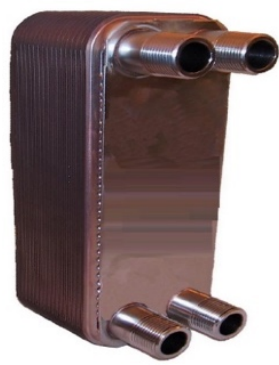

Fig. 2 A general view of plate heat exchanger

A water pump was used to provide circulation of the working fluid inside the plate heat exchanger. The required cold fluid flow rates $(3,4,5,6$ and $7 \mathrm{lpm})$ were adjusted and monitored during the tests. The experimental setup consists of two fluid loops, hot fluid and cold fluid, respectively. Cold fluid loop is open and water is discharged from the system after soaking up the heat from the hot fluid, whilst the hot one is closed and circulates between main heat exchanger and plate heat exchanger.

Table 2

\begin{tabular}{ll} 
Geometrical properties of the plate heat exchanger & \\
\hline Parameters & Value \\
\hline Plate length $(\mathrm{mm})$ & 208 \\
Plate width $(\mathrm{mm})$ & 76 \\
Port to port length $(\mathrm{mm})$ & 172 \\
Port to port width $(\mathrm{mm})$ & 42 \\
Plate thickness $(\mathrm{mm})$ & 0.4 \\
Number of corrugated plates & 16 \\
Chevron angle & $60^{\circ}$
\end{tabular}


The inlet and outlet temperatures of both cold fluid and hot fluid were measured by K- type thermocouples. The thermocouples were located for each inlet and exit points of plate heat exchanger. The exit temperatures of the cold fluid were set up as $40^{\circ} \mathrm{C}, 45^{\circ} \mathrm{C}$ and $50^{\circ} \mathrm{C}$ to observe the effects of temperature on the performance of the nanofluid.

First of all, deionized water was used as working fluid in the hot fluid loop. Then, $\mathrm{TiO}_{2}$ containing nanofluid was used as working fluid in the hot fluid loop and the obtained results were compared to each other. Each experiment repeated three times and the average values of them were used in the calculations. The experiments were repeated for 3 different cold fluid outlet temperatures for each flow rate aforementioned. Also, the hot fluid flow rate was kept constant at $19 \mathrm{lpm}$.

For validation of the problem and visualization the flow and temperature characteristics inside the plate heat exchanger, a series of numerical analysis were performed using a CFD software, ANSYS Fluent 16.

Mesh configuration of channels of the plate heat exchanger was presented in Figure 3. In the numerical study, grid independence analysis (mesh validation) was also conducted to show off the mesh independency. It was found that the optimum mesh number was about 12000000. The optimum mesh number was determined considering mean heat transfer rate. In order to compute heat transfer rate from the hot fluid to the cold fluid, temperatures and inlet flow rates in both fluid loop were employed.

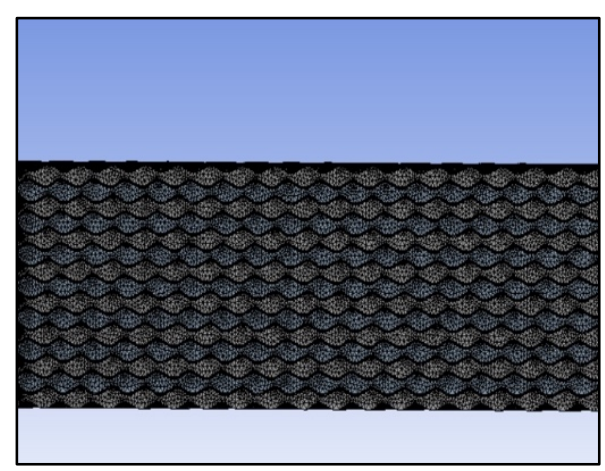

Fig. 3 Mesh structure of the channels

\section{Theoretical Analysis}

The taken heat from the hot sink $\left(\dot{Q}_{h}\right)$ and the absorbed heat by the cold side $\left(\dot{Q}_{c}\right)$ can be computed by following equations.

$$
\begin{aligned}
& \dot{\mathrm{Q}}_{\mathrm{h}}=\dot{\mathrm{m}}_{\mathrm{h}} \mathrm{c}_{\mathrm{p}, \mathrm{h}}\left(\mathrm{T}_{\mathrm{h}, \mathrm{i}}-\mathrm{T}_{\mathrm{h}, \mathrm{o}}\right) \\
& \dot{\mathrm{Q}}_{\mathrm{c}}=\dot{\mathrm{m}}_{\mathrm{c}} \mathrm{c}_{\mathrm{p}, \mathrm{c}}\left(\mathrm{T}_{\mathrm{c}, \mathrm{o}}-\mathrm{T}_{\mathrm{c}, \mathrm{i}}\right)
\end{aligned}
$$

The overall values between $\dot{Q}_{h}$ and $\dot{Q}_{c}$ were used in calculations because of the fact that there was a difference between extracted heat $\left(\dot{Q}_{h}\right)$ and the absorbed heat $\left(\dot{Q}_{c}\right)$, due to heat loss.

$\dot{\mathrm{Q}}_{\mathrm{ave}}=\left(\dot{\mathrm{Q}}_{\mathrm{h}}+\dot{\mathrm{Q}}_{\mathrm{c}}\right) / 2$
The overall heat transfer coefficient can also be computed by following equation:

$\mathrm{U}=\frac{\dot{\mathrm{Q}}_{\mathrm{ave}}}{\mathrm{A} \cdot \mathrm{LMTD}}$

where the logarithmic mean temperature difference (LMTD) is;

$L M T D=\frac{\left(T_{h, i}-T_{c, o}\right)-\left(T_{h, o}-T_{c, i}\right)}{\ln \left(\frac{T_{h, i}-T_{c, o}}{T_{h, o}-T_{c, i}}\right)}$

For plate heat exchangers, the Reynolds number could be calculated by means of Eq. [6].

$\operatorname{Re}=\frac{\mathrm{GD}_{\mathrm{h}}}{\mu}$

Similarly, the Prandtl number could be computed using Eq. [7].

$\operatorname{Pr}=\frac{\mu c_{p}}{k}$

Heat transfer coefficient could be calculated using Nusselt number;

$\mathrm{Nu}=\frac{\mathrm{hDh}}{\mathrm{k}}$

Using the correlation in below, the Nusselt number in plate heat exchanger can be obtained (Kakaç et al. 2012):

$\mathrm{Nu}=0.348 \mathrm{Re}^{0.663} \operatorname{Pr}^{0.33}$

Finally, the heat transfer coefficient of hot side could be calculated by using heat transfer coefficient of cold side and overall heat transfer coefficient;

$\mathrm{U}=\frac{1}{\frac{1}{\mathrm{~h}_{\mathrm{h}}}+\frac{1}{\mathrm{~h}_{\mathrm{c}}}+\frac{\Delta \mathrm{x}}{\mathrm{k}_{\mathrm{p}}}}$

\subsection{Uncertainty Analysis}

In order to specify uncertainties and evaluate the obtained data in an experimental study, an uncertainty analysis must be performed. This method is a powerful and reliable tool. In an experimental work, the uncertainties could arise from some parameters such as test conditions, calibration, instrument types and so on. In this study, flow rates and temperatures were measured by using suitable instruments.

The result $R$ is a given function in terms of the independent variables $\mathrm{x} 1, \mathrm{x} 2, \ldots, \mathrm{xn}$. WR is the uncertainty in the result and $\mathrm{w} 1, \mathrm{w} 2, \ldots, \mathrm{wn}$ are the uncertainties in the independent variables. If the uncertainties in the independent variables are all presented with the same odds, then the uncertainty in the finding having these odds is given by using the methodology developed by Holman (2001):

$$
\mathrm{W}_{\mathrm{R}}=\left[\left(\frac{\partial R}{\partial x_{1}} w_{1}\right)^{2}+\left(\frac{\partial R}{\partial x_{2}} w_{2}\right)^{2}+\cdots+\left(\frac{\partial R}{\partial x_{n}} w_{n}\right)^{2}\right]^{1 / 2}
$$

The accuracy of the thermocouples and the mass flow meter are $\pm 0.4{ }^{\circ} \mathrm{C}$ and $\pm 0.8 \mathrm{lpm}$, respectively. The uncertainty of the experimental results was specified depended on the deviation in experimental parameters. 
The experiments were replicated three times and average of the temperatures at each experiment was utilized. The overall uncertainty of the experiments lies within $\pm 5.13 \%$ based on Eq. [1]. When the overall uncertainties of the measured variables were evaluated, it is seen that they were in an acceptable range.

\section{Results and Discussion}

First of all, the experiments were performed by using deionized water as working fluid in the hot loop. Then, $\mathrm{TiO}_{2}$ /deionized water nanofluid was used as working fluid in the hot flow loop and the results of them were compared to each other. When the system attained to steady-state conditions, the data were monitored and recorded via data acquisition system. The obtained heat transfer coefficients via Reynolds number and cold fluid exit temperatures were illustrated in Figure 4 for each working fluid. It is seen from this figure that, $\mathrm{TiO}_{2} /$ deionized water nanofluid usage as the working fluid enhanced the heat transfer coefficient of plate heat exchanger. An average increment of $8 \%$ in heat transfer coefficient was obtained by using nanofluid as the working fluid in plate heat exchanger. Similar results were also reported by Barzegarian et al. (2016) for the overall heat transfer coefficient.
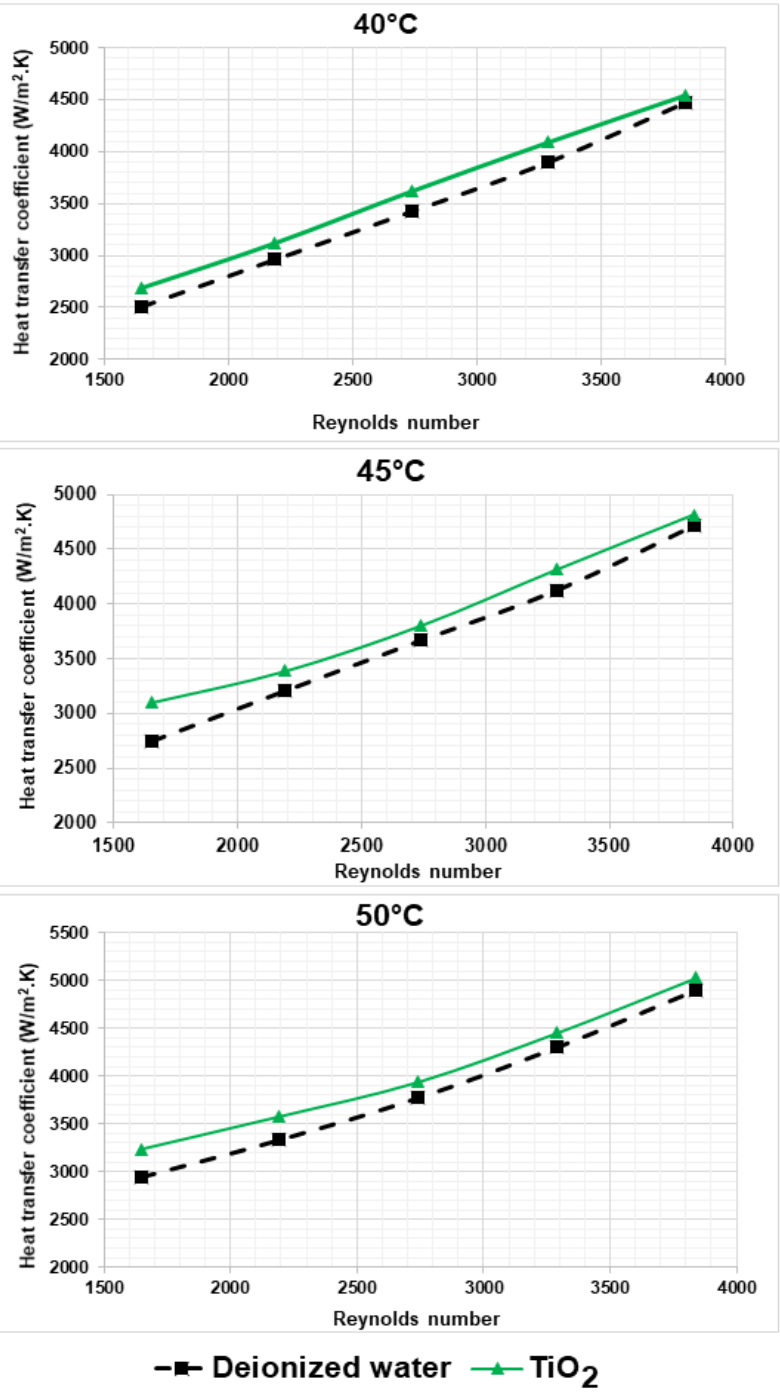

Fig. 4 Heat transfer coefficient values for different operating conditions
The numerical analysis were performed only for TiO2 nanofluid and both results were compared to each other. Figure 5 shows the transferred heat in the plate heat exchanger via Reynolds number for various cold fluid exit temperatures. The transferred heat displayed an increasing trend with increasing the flow rate in plate heat exchanger for $\mathrm{TiO}_{2}$ nanofluid. It was also observed that experimental and numerical results were in good agreement with each other. The maximum deviation between experimental and numerical data was $10 \%$ for all cases.

In numerical analysis, the flow regime was investigated and velocity contours presented in Figure 6 were obtained. While examining these figures, the effects of increasing mass flow rate was clearly seen. As the mass flow rate increases, turbulence intensity increases because of the plate geometry. As a result, heat transfer rate was also increased.
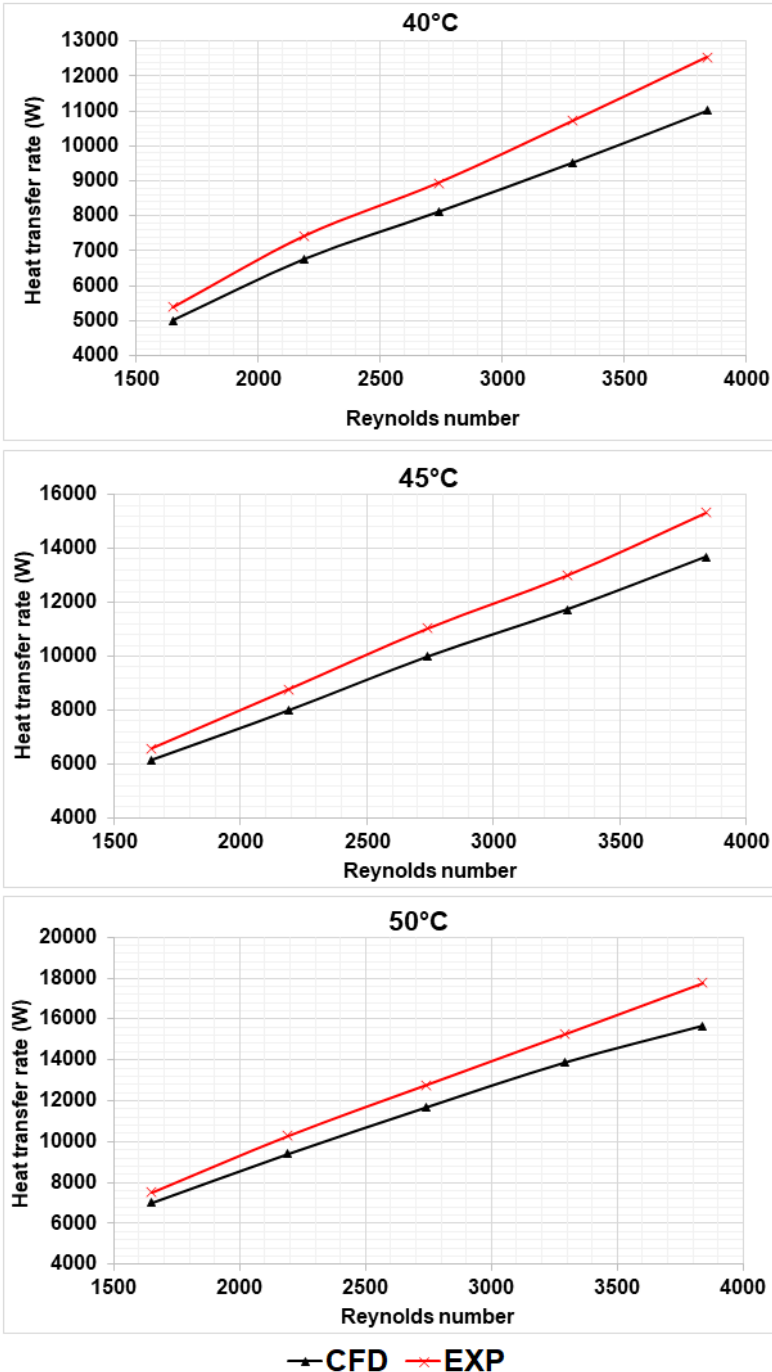

Fig. 5 Transferred heat via Reynolds number

It is a well-known fact that pressure drop is an important parameter for plate heat exchanger. So, the pressure drop inside the plate heat exchanger was numerically investigated. Figure 7 shows the pressure drop in hot side of the plate heat exchanger, when $\mathrm{TiO}_{2}$ nanofluid was employed as working fluid. The pressure drop was found as $1.065 \mathrm{kPa}$. 

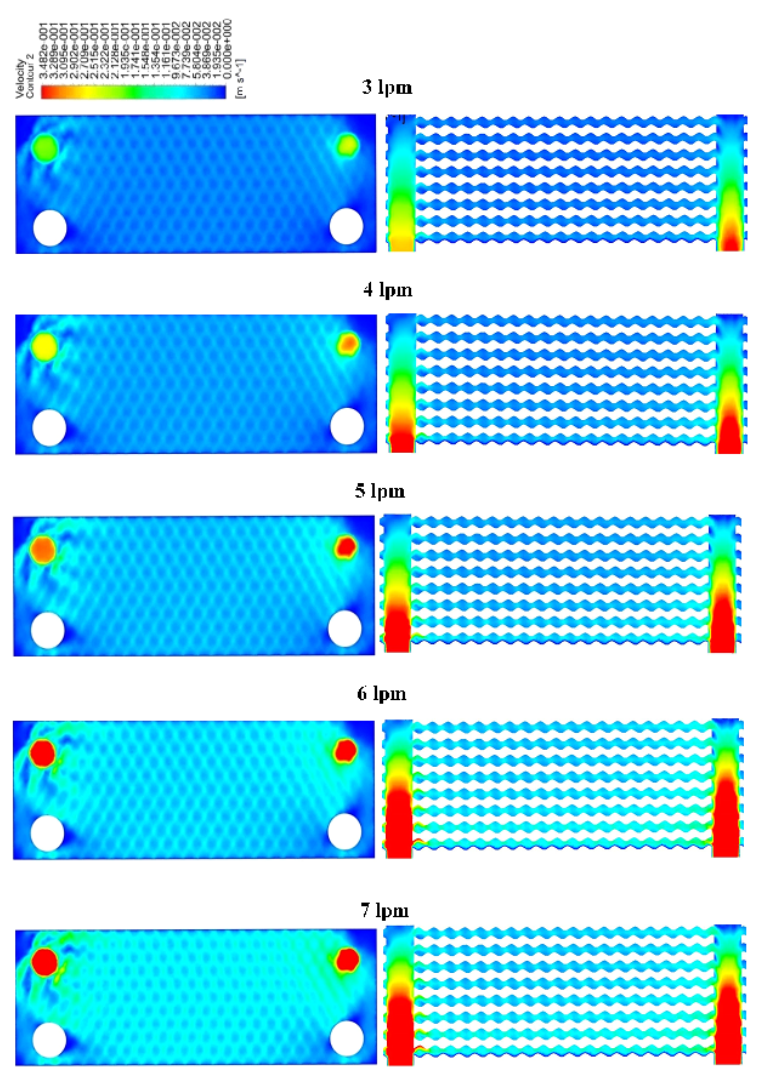

Fig. 6 Velocity contours for various mass flow rates

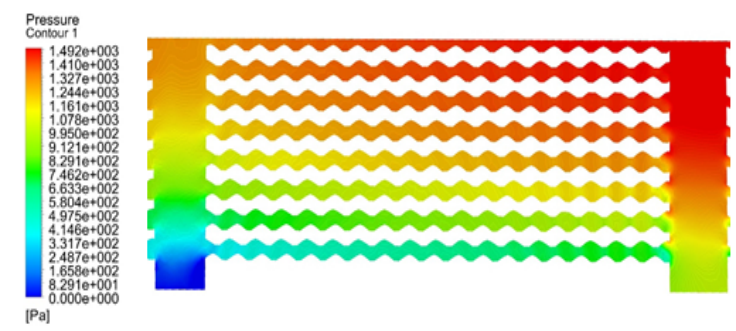

Fig. 7 Pressure contour in hot side of the plate heat exchanger

\section{Conclusions}

In this study, thermal performance of a plate heat exchanger using $\mathrm{TiO} 2$ nanofluid as working fluid was experimentally and numerically investigated. According to the experiments performed in this study, CFD approach can be a valuable tool to find out performance of plate heat exchangers and optimization of temperatures, design and so on.

Furthermore, the effects of fluid flow rate and temperature on heat transfer improvement was examined. The outcomes of this study are as flows:

- TiO2/deionized water nanofluid usage as the working fluid in a plate heat exchanger upgrades the heat transfer coefficient significantly.

- Heat transfer coefficient increases based on increment in flow rate.

- CFD approach can be readily utilized to determine the thermal characteristics of the plate heat exchangers.

\section{Nomenclature}

$A \quad$ total heat transfer area, $\mathrm{m} 2$

$c_{p} \quad$ specific heat capacity (J kg-1 K-1)

$D_{h} \quad$ hydraulic diameter (m)

$G \quad$ mass velocity (kg m-2 s-1)

$h \quad$ heat transfer coefficient (W m-2 K-1)

$k \quad$ thermal conductivity (W m-1 K-1)

LMTD log mean temperature difference $(\mathrm{K})$

$\dot{m} \quad$ mass flow rate (kg s-1)

$\mathrm{Nu} \quad$ Nusselt number

Pr Prandtl number

$\dot{Q} \quad$ heat transfer rate (W)

Re Reynolds number

$T$ temperature $\left({ }^{\circ} \mathrm{C}\right)$

$U \quad$ overall heat transfer coefficient (W m-2 K-1)

$\mathrm{W}_{\mathrm{R}} \quad$ the total uncertainty (\%)

$w_{1}, w_{2}, w_{n}$ the uncertainties in the independent variables $\mu \quad$ dynamic viscosity $(\mathrm{kg} \mathrm{m}-1 \mathrm{~s}-1)$

$\Delta x \quad$ plate thickness (m)

\section{Subscripts}

$\begin{array}{ll}\mathrm{c} & \text { cold } \\ \mathrm{i} & \text { Inlet } \\ \mathrm{h} & \text { hot } \\ \mathrm{o} & \text { outlet } \\ \mathrm{p} & \text { plate } \\ \mathrm{R} & \text { the function uncertainty }\end{array}$

\section{References}

Barzegarian, R., Keshavarz Moraveji, M. \& Aloueyan, A. (2016) Experimental investigation on heat transfer characteristics and pressure drop of BPHE (brazed plate heat exchanger) using $\mathrm{TiO}_{2}$-water nanofluid. Experimental Thermal and Fluid Science, 74, 11-18.

Behrangzadeh, A. \& Heyhat, M.M. (2016) The effect of using nano-silver dispersed water based nanofluid as a passive method for energy efficiency enhancement in a plate heat exchanger. Applied Thermal Engineering, 102, 311-317.

Han, X.H., Cui, L.Q., Chen, S.J., Chen, G.M. \& Wang, Q. (2010) A numerical and experimental study of chevron, corrugatedplate heat exchangers. International Communications in Heat and Mass Transfer, 37, 1008-1014.

Holman, J. P. (2001) Experimental Methods for Engineers (7th edition). New York: McGraw-Hill.

Huang, D., Wu, Z. \& Sunden, B. (2016) Effects of hybrid nanofluid mixture in plate heat exchangers. Experimental Thermal and Fluid Science, 72, 190-196.

Kabeel, A E, El Maaty, T.A, \& El Samadony, Y. (2013) The effect of using nano-particles on corrugated plate heat exchanger performance. Applied Thermal Engineering, 52, 221-229.

Kakaç S., Liu H. \& Pramuanjaroenkij A. (2012) Heat Exchangers: Selection, Rating, and Thermal Design. Florida, USA: CRC Press.

Kan, M., Ipek, O. \& Gurel, B. (2015) Plate heat exchangers as a compact design and optimization of different channel angles, Acta Physica Polonica, 12, 49-52.

Kumar, V., Tiwari A. K., \& Ghosh, S.K. (2016). Effect of chevron angle on heat transfer performance in plate heat exchanger using $\mathrm{ZnO} /$ water nanofluid, Energy Conversion and Management, 118, 142-154.

Pandey, S.D. \& Nema, V.K. (2012) Experimental analysis of heat transfer and friction factor of nanofluid as a coolant in a corrugated plate heat exchanger, Experimental Thermal and Fluid Science, 38, 248-256.

Sarafraz, M. \& Hormozi, F. (2016) Heat transfer, pressure drop and fouling studies of multiwalled carbon nanotube 
nanofluids inside a plate heat exchanger. Experimental Thermal and Fluid Science, 2016, 72, 1-11.

Serebryakova, M.A. Dimov, S.V., Bardakhanov, S. P. \& Novopashin, S. A. (2015) Thermal conductivity, viscosity and rheology of a suspension based on $\mathrm{Al}_{2} \mathrm{O}_{3}$ nanoparticles and mixture of $90 \%$ ethylene glycol and $10 \%$ water, International Journal of Heat and Mass Transfer, 83, 187-191.

Taghizadeh-Tabari, Z., Zeinali Heris, S., Moradi, M. \& Kahani, M. (2016) The study on application of $\mathrm{TiO}_{2} /$ water nanofluid in plate heat exchanger of milk pasteurization industries. Renewable and Sustainable Energy Reviews, 58, 1318-1326.

Tiwari, A.K., Ghosh, P. \& Sarkar, J. (2013). Performance comparison of the plate heat exchanger using different nanofluids. Experimental Thermal and Fluid Science, 49, 141-151.

Tiwari, A.K., Ghosh, P., Sarkar, J., Dahiya, H. \& Parekh, J. (2014) Numerical investigation of heat transfer and fluid flow in plate heat exchanger using nanofluids. International Journal of Thermal Sciences, 85, 93-103.

Yang, J., Jacobi, A. \& Liu, W. (2017) Heat transfer correlations for single-phase flow in plate heat exchangers based on experimental data. Applied Thermal Engineering, 113, 1547 1557. 